\title{
FAMILIAL GLAUCOMA*
}

\author{
BY \\ D. G. MACPHERSON \\ Hove \\ AND \\ K. J. MODI \\ Sussex Eye Hospital, Brighton, Sussex
}

FAMILIAL primary glaucoma is a recognized entity. It has been reported in the literature quite regularly, though not frequently.

Benedict (1842) was the first to recognize the familial inheritance of glaucoma, and other authors followed with large collections of such cases. Something like 18 per cent. of the total cases of glaucoma show an hereditary component (Havener, 1955).

Duke-Elder (1940) stated that the inheritance was dominant and could be transmitted by each sex, the transmitting parent being usually affected. The trait being dominant, the succeeding generation shows anticipation (von Graefe, 1869). The onset of familial glaucoma occurs some 20 years earlier than other primary cases of glaucoma, and the offspring develops glaucoma some 10 years earlier than the parent.

Recently we came across a family of a father and his three sons all suffering from primary glaucoma, which typifies the above statement in many details.

\section{Case Reports}

Case 1, a man aged 19 years (II, 2) came with a complaint of haloes and blurred vision. He volunteered that two of his brothers suffered from similar complaints and this his father had had his eyes operated on. The visual acuity was normal. The fundi showed cupped discs. The peripheral fields showed upper nasal defects in the right eye and the central fields showed an upper arcuate scotoma in the right eye. The intra-ocular pressure was $40 \mathrm{~mm}$. $\mathrm{Hg}$ in each eye at the first examination.

Case 2, a man aged 21 years (II, 1) complained of occasional haloes, eye ache, and misty vision since the age of 16 . The discs were cupped. There were defects in peripheral fields but the central fields were full. The ocular tension was $40 \mathrm{~mm}$. Hg in the right eye and $30 \mathrm{~mm} . \mathrm{Hg}$ in the left at the first examination.

Case 3, a man aged 17 years (II, 3) complained of haloes. The visual acuity was normal. The discs were not cupped. The peripheral fields showed upper nasal defects and the central fields showed an early arcuate scotoma. The ocular tension was $30 \mathrm{~mm}$. $\mathrm{Hg}$ in each eye at the first examination.

* Received for publication November 23, 1960. 
Case 4, a man aged 52 years $(I, 1)$ had bilateral trephines at the age of 34 years. The discs were cupped, and the peripheral fields markedly contracted-the left more than the right. The trephines were draining and the tension normal. The visual acuity was $6 / 9$ partly in the right eye and 6/24 in the left since the operation.

Gonioscopy on the three brothers showed that the angles were open but covered with pigmented trabeculae. There were also short, distended, convoluted blood vessels either concentric to the angle or running radially towards the pupil for a short distance. Phasing also showed a persistent rise in the intra-ocular pressure above the normal.

Bilateral trephines (D.G.M.) were carried out and the tension was brought down satisfactorily in each case.

\section{Summary}

A family showing hereditary glaucoma is reported. The affected father's family background did not reveal any relation with a history of blindness or poor sight.

Short congestive attacks causing haloes is an interesting feature in these cases. Pigmented trabeculae and unusual blood vessels in an otherwise open angle seem to have had an adverse affect on the draining mechanism.

\section{REFERENCES}

BenEDict, T. W. G. (1842). "Abhandlungen aus dem Gebiete der Augenheilkunde", vol. 1. Breslau. Cited by Duke-Elder (1940).

Duke-Elder, S. (1940). "Text-book of Ophthalmology", vol. 3, p. 3331. Kimpton, London. Graefe, A. von (1869). v. Graefes Arch. Ophthal., 15, pt. 3, p. 108.

Havener, W. H. (1955). Amer. J. Ophthal., 40, 828. 